SEX DIFFERENCES IN BEHAVIORAL AND PSYCHOLOGICAL EXPRESSION OF GRIEF DURING ADOLESCENCE: A META-ANALYSIS

By

RACHEL MARIE SHULLA

\author{
A Thesis Submitted to The Honors College \\ In Partial Fulfillment of the Bachelors degree With Honors in \\ Family Studies and Human Development \\ THE UNIVERSITY OF ARIZONA
}

MAY 2017

Approved by:

Russell Toomey, Ph.D.

Norton School of Family and Consumer Sciences 


\begin{abstract}
Adolescence is a time of emotional growth and maturity, as well as increased autonomy. With such environmental changes, combined with specific age-related neurological development, adolescent behavioral research has documented a collection of age-specific behaviors universally observed during this time in development. Adolescent egocentric behaviors have been documented for years, and grief during this developmental period can exacerbate these behaviors. This meta-analysis synthesizes the results of 14 independent studies ( $N=6,979$ participants) that examined sex differences in internalized, externalized, and PTSD symptoms associated with grief during adolescence. While no mean-level differences were found between adolescent females and males in externalizing behaviors associated with grief $(d=0.03)$, on average, females reported higher levels of internalized grief responses $(d=0.18)$ and higher levels of PTSD symptoms $(d=0.36)$ than their male counterparts. Findings suggest the need for additional, more nuanced research to investigate possible sex differences in externalized behaviors relating to grief. In addition, research should examine whether tailored therapeutic and intervention measures and resources are needed for adolescents experiencing internalized grief and PTSD symptoms given sex differences in these reactions.
\end{abstract}




\section{Sex differences in Behavioral and Psychological Expression of Grief During Adolescence: A Meta-Analysis}

Grief manifests itself in many different ways. Often associated with grief are feelings of anger, hostility, and immense sadness or depression, as well as so many other internalized and externalized expressions (Worden, 2003). In addition, grief may appear through post-traumatic stress disorder (PTSD) symptoms (Mitchell \& Terhorst, 2017). By senior year of high school, approximately $90 \%$ of adolescents have experienced the death of a family member or friend (Ens \& Bond, 2005), with approximately 3-5\% of those individuals experiencing a parental death (Garmezy \& Masten, 1994). Thus, there is a compelling need to understand how deaths experienced during adolescence are associated with internalizing, externalizing, and PTSD symptoms.

The period of adolescence is a time of many developmental and life changes, such as increases in academic rigor, autonomy-seeking, emotional development, and rapid physical growth and change (Shifflet-Chila et al., 2016; Tau \& Peterson, 2010). The timing of and extent to which developmental changes affect an adolescent are partially determined by an adolescent’s sex assigned at birth (Perry \& Pauletti, 2011). The timing of the maturation of brain structures and subsequent functionality differs by sex assigned at birth (Christakou et al., 2009), and these differences play a role in an adolescents’ behavioral response to ongoing environmental change (Casey et al., 2008). As both brain development and behavior vary by sex during adolescence, it is important to explore how these differential changes in adolescent development can influence the exhibitions of grief responses (i.e., externalizing problems, internalizing problems, and PTSD 
symptoms). This meta-analysis examined sex differences in internalized and externalized expressions of grief and PTSD symptoms during adolescence.

\section{Grief and Adolescent Emotion Regulation}

Adolescents cope to stressful stimuli by adapting to better handle their environment (Aronfreed, 2013). Reactions to a stressor can be coded as internalized or externalized coping behaviors. Internalized behaviors involve reacting to a stressor by focusing inward, and may include depression, anxiety, loneliness, withdrawal, or suicidal ideation (Bornstein et al., 2013). Externalized behaviors include those directed towards the adolescent's environment and may involve other objects or people; these responses can include impulsivity, aggression, attention difficulties, loosing a temper, or delinquency behaviors (Herres et al., 2016). With repeated need for adaptive functioning overtime in order to cope with their environment, an individual may develop internalized and/or externalized behavioral problems (Reijneveld et al., 2014). A behavioral problem occurs when the consequences of an adaptive behavior interferes with daily functioning (Bornstein et al., 2013). Such behavioral responses have the potential to be maladaptive, resulting in new, negative behaviors in order to reach equilibrium (Schneiderman et al., 2008). Further, striving for a level of homeostasis that allows for survival against repeated stressors requires continuous energy (Hobfoll, 1989). Negative behavioral outcomes emphasize the important roles adaptive stress responses.

PTSD occurs after witnessing, hearing, or having first-hand direct exposure to a stressful or traumatic experience and is prevalent among adolescents (Abate et al., 2017). The effects from PTSD are unique in that they affect both the mental health of an individual, and the physical behaviors they exhibit (Danielson et al., 2017). As the 
behavioral manifestations of PTSD are so vast, it is important to consider PTSD as a separate entity from internalizing and externalizing disorders.

\section{Grief and Adolescent Brain Development}

The adolescent brain undergoes rapid maturation. In terms of brain development relevant to grief during adolescence, the prefrontal cortex and the limbic system play the most crucial roles (Casey et al., 2008). The prefrontal cortex is involved in cognitive control (Dixon, 2015). The dense white matter involved with myelination of the prefrontal cortex develops later in adolescence (Riva \& Giorgi, 2000). This indicates that the prefrontal cortex is one of the last brain regions to mature, which renders executive cognitive communication unpredictable during adolescence (McGuire \& Botvinick, 2010). On the other hand, the limbic system, including the amygdala, the hippocampus, and the hypothalamus, found deep in the cerebrum, is primarily involved in processing emotional information (Nieuwenhuys, 1996), which is found to be exaggerated among adolescents when compared to children or adults (Arain et al., 2013). That is, there is an overproduction of axons and synapses involved in the limbic region that supports communication of emotions during adolescence (Casey et al., 2008), resulting in greater emotional reactivity due to high limbic system activity and low prefrontal cortex involvement. Towards late adolescence and early adulthood, programmed apoptotic cell death and neurogenesis (Nuñez et al., 2001; Rankin et al., 2003), in addition to synaptic pruning which removes the overproduction of axons and synapses in the limbic system, leaves a more balanced communication pathway between the emotional limbic system and the prefrontal cortex (Blakemore, 2008). The delayed maturation of the prefrontal cortex and the overactive limbic system indicates a potential for more significant 
behavioral and emotional reactions during the time of adolescence, particularly in reaction to stressors like the loss of a loved one or family member.

Studies have identified sex differences in brain structure and size (Leonard et al., 2008), and these differences vary by chronological age (Ruigrok et al., 2014). First, across the lifespan, males have an average of $10 \%$ larger brain volume compared to females (Ruigrok et al., 2014; Paus et al., 2017). In addition, across all age groups, males consistently show a relatively stable 9 to $14 \%$ larger cortical gray matter and peak density occurs at the age of 14.5 years among males versus peak female brain size at 10.5 years (Giedd et al., 2012). White matter, due to myelinated axons, grows more rapidly in males than females (Perrin et al., 2008). This higher density of white matter in males indicates a sexual dimorphism seen across all ages of development (Paus, 2010).

In addition to white and gray matter, sex differences in brain size and development can be seen in the limbic system, specifically the amygdala and hippocampus (Gur et al., 2002). A high density of androgen receptors are found in the amygdala, while a high number of estrogen receptors reside in the hippocampus (Giedd et al., 2012). When evaluated during adolescence, males are seen to have larger gray matter volume in the amygdala while females have a larger hippocampus (Giedd et al., 1997; Neufang et al., 2012). Behavioral reactivity from activation in brain regions that exhibit sex differences may show not only an increased emotional response in adolescence, but also increase the sex gap in behavioral and emotional responses to grief.

\section{Combining Sex, Brain Structure, and Behavior}

The differences in brain structure sizes in males compared to females can be applied to known internalized and externalized behaviors that are linked to different areas 
of the brain. One example that encompasses sex differences in behavior and brain structure is the extensively studied history of depression. Adolescent females are two times more likely than adolescent males to be diagnosed with anxiety and depression during adolescence (Rutter et al., 2003). Relating to neuroimagry, this is not surprising, as depression and anxiety have been linked to disrupted hormone levels, particularly estrogen, as well as differing hippocampal volumes (Albert, 2015).

The prevalence of a major depressive episode lasting at least 30 days is about $2 \%$ in childhood, then climbs to $6 \%$ in adolescence, and begins to decline in early adulthood (Costello et al., 2002). The increased rates of depression are in conjunction with reduced activity in the left dorsolateral prefrontal cortex (dlPFC) (Engels et al., 2010). The dlPFC is a superiorly located brain region in the prefrontal cortex is most associated with sensory input from associated brain regions, of which include the amygdala and hippocampus, and exudes cognitive as well as executive functions based on emotion sensory inputs (Koenigs \& Grafman, 2009). In addition to the decline in activation of the dlPFC during depression (Frodl et al., 2006), it has been found depressed individuals have increased levels of amygdala activity (Hamilton et al., 2008). Furthermore, depression is also associated with smaller hippocampal volumes and experienced a continuum with a decreasing hippocampal size indicating poorer performances on depression analysis (Frodl et al., 2006).

Females have a slightly smaller baseline amygdala and larger hippocampal volume compared to males, but in contrast, depressed individuals, including both males and females tend to have smaller hippocampal size and larger amygdala activation as well as decreased activity in the dlPFC. (Koenigs \& Grafman, 2009). While it is not fully 
understood why adolescent females are more at risk for depression, it is theorized that sex differences may be due to the high levels of sex hormone receptors resulting in higher levels of depression in females (Angold et al., 1999). Thus, it is possible that requiring a predetermined larger hippocampal size in females, any disruption in size could result in exacerbated behavioral responses.

Disruption in the normal baseline differences in brain structure size can be seen during adolescence due to both the rapid maturation of brain structures, and the formation of neuronal pathways for communication (Thapar et al., 2012). This quick development of specific immature brain structures during adolescence allows for much discrepancy when the genetic influences as stated above, as well as environmental influences, contribute to the way the brain structure ultimately develops (Thapar et al., 2012). The result of grief is often an immense level of stress on the body. For adolescents, in particular, stress adaption can be difficult (Cohen \& Mannario, 2016). The hippocampus, prefrontal cortex, and amygdala that rapidly mature during adolescence have been shown to be the brain structures most affected during stress (Giedd \& Rapoport, 2010). This puts adolescents at an increased risk of behavioral reactivity to stress (Romeo, 2014), and thus grief. The objective for this meta-analysis is to determine the extent to which sex differences in internalized and externalized expressions of grief during adolescence exist. Specifically, this meta-analysis investigates sex differences of internalized behavior, externalized behavior, and PTSD symptoms related to grief during adolescence.

\section{Method}

\section{Literature Search}


Quantitative studies that reported sex differences in grief responses during adolescence were identified using several online databases: PsycInfo, PsycArticles, Academic Search Complete, ERIC, and Medline. For each database, the same combinations of keywords were used: “adolescent OR teen OR adolescence OR youth” and "grief OR bereavement” and "gender OR sex". The online database search took place in September of 2016, and results were narrowed by publication year to only include published studies from January 2001 to September 2016. All studies included the analysis were published after 2001 to achieve a more accurate representation of the grief experiences of contemporary adolescents. In total, 325 studies fit the inclusion criteria (see Inclusion and Exclusion Criteria section). Of these studies, 111 were identified as duplicates, resulting in a total of 214 unique studies. After excluding studies that did not fit the criteria for reasons discussed below, 14 studies were included in the analysis.

\section{Inclusion and Exclusion Criteria}

For a study to be included in this meta-analysis, four inclusion criteria were applied. First and foremost, this study investigated adolescents aged 18 years or younger. The studies that were included were narrowed to an average minimum age of 8.31 and an average maximum age of 16.79. Studies included in the analysis either limited their sample to adolescents or conducted separate analyses with participants in subgroups by age range (i.e., childhood vs. adolescence vs. adulthood). Second, the adolescent reporting on grief in the study must have known the individual who died (i.e., a direct relationship; parent, sibling, close friend). Third, data collected in the included studies needed to report on internalized behaviors, such as depression or anxiety, externalized behaviors, such as self-harm or delinquency, or PTSD symptoms, such as sensitivity to 
particular stimuli or flashbacks for inclusion. Finally, sex differences in these behaviors needed to be reported or available to allow for a comparative analysis of behavior in adolescence by sex.

Studies were excluded from analysis if they reported qualitative data. Studies were not included if the adolescent reported their grieving reactions to a person with a terminal illness who had not yet died. Studies were also excluded if they did not report or were unable to provide disaggregated data based on sex, or if the age range varied too widely across the lifespan and separate analyses were not available upon request. Finally, studies were also excluded if the death occurred when the participant was an adolescent but data collection occurred during adulthood.

\section{Reported and Coded Data}

Studies included interviews, questionnaires, surveys, and self-report measures to obtain data. Furthermore, scales used to evaluate behaviors varied across studies; thus, Cohen's $d$ s were calculated in order to standardize the difference in mean values between male and female adolescents on the three separate outcomes evaluated (i.e. internalizing, externalizing, and PTSD). Cohen's $d$ values were calculated $d=\left(M_{1}-M_{2}\right) / s d_{\text {pooled }}$ with $M_{1}$ as the adolescent male mean for a subgroup, $M_{2}$ as the adolescent female mean for a subgroup, and $s d_{\text {pooled }}$ as the standard deviation of the subgroup pooled sample (Card, 2016). Positive Cohen's $d$ values indicated that adolescent females engaged in a particular outcome more frequently than adolescent males, and negative values reflect the opposite relationship. Cohen’s $d$ values are not bound by an integral (i.e., \pm 1.00 ) meaning the farther away the value is from 0 , the larger the difference. The use of a fixed effects model was to deduce a conclusive finding as to which sex exhibited the subgroup 
behavior more often during grief, thus eliminating generalizations or interpretive results by combining the single effect size for a study with the deviation of the study from the total population effect size. Effect sizes were weighted based on number of participants (Card, 2016). Q values were calculated to represent the extent of heterogeneity in the analysis and $I^{2}$ was used to quantitatively display the percent variability in the effect size (Card, 2016). Several study and sample characteristics were coded: mean age; percent male; race and ethnicity; geographic location of the study; the relationship the adolescent had to the individual who had died; whether the death was expected, unexpected, or occurred from suicide or a natural disaster; year of data collection; and time elapsed since the death occurred.

\section{Results}

Of the 14 independent studies comprising this meta-analysis (see Table 1), 6,979 participants were included. The mean age of the participants was 12.22 years $(S D=2.31)$. The average minimum age of participants was 8.31 years of age while the average maximum age of participants was 16.79 years. Across studies, the participants were equally represented in terms of sex assigned at birth: 50\% male and 50\% female. Asian and white participants comprised most of the participants with $60.43 \%$ and $36.59 \%$ respectively. Studies $(n=6)$ were conducted in the United States and Canada, Europe (n =6), as well as one from Japan and another located in South Africa. The duration between the time of death and the time the of data collection ranged from 1 month to 9.5 years with an average lag time of 27.48 months.

The studies included a representative sample of types of losses including those that were expected $(n=7)$ and unexpected $(n=7)$; of the unexpected deaths, suicide was 
frequently a contributing reason $(n=5)$. Only one study investigated grief after a natural disaster (i.e., death by earthquake or natural disaster-related fatal injuries). Most studies included participants who have lost a parent $(\mathrm{n}=11)$, with some examining the death of a sibling $(n=6)$. Other studies incorporated the death of a grandparent, classmate, or someone they really cared about $(n=4)$. Of the studies that investigated the death of a grandparent, classmate, or someone they really cared about, adolescents who have lost a parent or sibling were also included. Only one study investigated exclusively the death of a grandparent.

\section{Internalizing Behaviors}

Internalizing behaviors of grief studies focused on anxiety and depression. Six of the 14 included studies collected data on internalizing behaviors related to grief. The difference between adolescent males and females experiencing internalized expression of grief ranged from -0.67 to 0.65 across studies (see Figure 1). An average effect size was calculated through a weighted fixed effects model. Using Cohen’s guidelines for interpreting effect sizes ("small” d=0.2, “medium" $\mathrm{d}=0.5$ and "large” $\mathrm{d}=0.8$ ), an analysis of internalizing behaviors revealed a small effect size $(d=.18)$. This finding suggests that adolescent females were slightly more likely than males to exhibit internalizing behaviors related to their grief. Tests of heterogeneity revealed significant variability in this effect size $\left(\mathrm{Q}_{\text {Total }}(d f=5)=34.28, p<.001\right)$, with $I^{2}=82.5 \%$.

\section{Externalizing Behaviors}

Studies investigated several externalizing behaviors of grief included behaviors such as self-injury, hyperactivity, delinquency, and peer and conduct problems. Nine studies were included that reported externalizing behaviors of adolescent grief. The 
difference between adolescent boys and girls experiencing externalized grief ranged from -0.54 to 0.70 across studies (see Figure 1 ). The average weighted effect size was close to zero $(d=.03)$, suggesting that there was no difference between adolescent males and females in externalized behaviors of grief. Importantly, tests of heterogeneity revealed considerable and significant variability within this effect $\left(\mathrm{Q}_{\text {Total }}(d f=8)=118.22, p<\right.$ $.001)$, with $I^{2}=94.92 \%$.

\section{PTSD Symptoms}

PTSD is unique in the fact that it cannot be exclusively included as an internalizing or externalizing behavior. Rather, separating PTSD into its’ own category allows for a better understanding of the prevalence grieving adolescents experience PTSD. Of the four studies that collected data on PTSD symptoms after a death, all four reported girls were more likely to experience PTSD (Cohen's $d$ s ranged from 0.16 to 0.46). The average weighted effect size showed a small to medium mean difference ( $d=$ .36). Tests of heterogeneity revealed no significant variability across studies $\left(\mathrm{Q}_{\mathrm{Total}}(d f=\right.$ 3) $=8.67, p<.001$ ), with $I^{2}=0.01 \%$. These tests indicate that female adolescents were more likely to experience PTSD symptoms after a loss compared to male adolescents, and that this difference is consistent across studies.

\section{Discussion}

The findings of this meta-analysis suggest that female adolescents are more likely than male adolescents to exhibit internalized symptoms as well as PTSD symptoms as grief responses to the death of family member of friend. Equally significant, this metaanalysis found no difference by sex in the likelihood of an adolescent engaging in externalizing behaviors when faced with the death of a family member or friend. Yet, it is 
important to note that while this meta-analysis provides the literature with more conclusive summary information about the effects of grief during a particular age and across sex categories, it is likely that an individual will exhibit a collection of behaviors of varying degrees. For example, while adolescent females were more likely to report signs and symptoms of PTSD grief responses, the conclusion that adolescent males do not display PTSD symptoms after grief is not what our data imply. Rather, grieving behaviors observed for both males and females should be understood as occurring on continuum with behavioral tendencies of fluctuating quantities.

Moreover, adolescents are not the only population subject to grieving behaviors. However, due to adolescents' very active limbic systems (Casey et al., 2008), adolescents are potentially more susceptible to the emotional and behavioral repercussions and manifestations related to the death of a family member or friend compared to children and adults. As behaviors, coping mechanisms, and emotional development mature throughout adolescence (Blakemore, 2008), studying grieving responses in adolescence is arguably important in order to assist in the optimal developmental of an individual. In other words, the experiences that occur during adolescence have the ability to shape the individual throughout adulthood. This carry-over effect can be seen through the longterm effects of grief during adolescence as studies have indicated grief predisposes an adolescent to detrimental health outcomes later in life (Brent et al., 2012), as well as an increase in likelihood of mental illness in adulthood (Boelen \& Spuij, 2013). Negative external behavior responses, such as delinquency, can also continue for a grieving adolescent throughout adulthood (Melhem et al., 2011). Understanding and intervening in 
the adolescent bereavement process has the potential to benefit the individual and society for decades (Green et al., 1984)

\section{Sex Differences: Implications for Intervention}

We found that adolescent females were slightly more likely to exhibit internalizing grieving behaviors and PTSD responses to death compared to adolescent males. Within our subsample of internalizing behaviors in this study, only two studies showed a small to moderate strength mean-level difference indicating adolescent males were more likely to exhibit internalizing behaviors (Haine et al., 2006; Kalter et al., 2003). These studies, like their counterparts that indicated female adolescents internalize grief more than male adolescents, studied a mixture of causes of death, including those that were expected, unexpected and by suicide. Also, variations could not be attributed to the data collection method, nor the race or ethnicity of the samples. However, only when the death occurred more recently (19 months or less) were adolescent males more likely to display internalizing behaviors compared to females. As duration between time of death and survey completion lengthened, there was a shift from adolescent males experiencing more internalizing grief to adolescent females about two years after the death.

Due to the small number of studies that were included in the subgroups examining internalized behaviors, it is not possible to conclusively attribute time elapsed between death and survey to the sex differences in internalizing behaviors. Nonetheless, this trend should be examined in future research, as it would have important implications for intervention practices. In addition to differing brain structures at play, such as female's larger hippocampus (Neufang et al., 2012), possibly resulting in longer-term 
repercussions of grief during adolescence, it is important to understand what other factors may be influential. Environmental pressures, such as public stigma may be at play. For example, adolescent males are potentially more negatively affected by the stigma of internalizing behaviors like depression (Gearing et al., 2015). This finding could explain the periodic shift away from adolescent male grief, as they may not feel the social and familial support, but rather ostracized by their grief when their peers are not exhibiting the same behaviors. The stigma behind mental health itself needs to be addressed to incorporate support services, family engagement, and academic assistance.

Similar to internalizing symptoms, a small to medium effect size was seen in female adolescents being more likely to exhibit PTSD symptoms associated with grief compared to male adolescents. Importantly, there was no variability across studies in this comparison by sex. This finding is important when keeping in mind the possible longterm effects of a death during adolescence as PTSD symptoms can reemerge or manifest throughout a person's lifetime and are prevalent years after the death (Green et al., 1984). The studies that reported PTSD symptoms often included unique situations of loss ranging from the death of a parent from AIDS (Culver, 2007) to sudden death from a natural disaster (Usami et al., 2012). Also included in these studies were instances of PTSD from death by suicide (Culver, 2007; Boelen \& Spuij, 2013).

Treatment for PTSD is limited; for example, 36\% of adolescents drop out of therapies that focus on trauma (Imel et al., 2013). In addition, PTSD treatment therapies do not always show improvements in individuals, thus limiting their effectiveness and desirability as a resource for adolescents who have PTSD (Steenkamp et al., 2015). Rather than being an indicator of how to shape PTSD therapies, the frequency of female 
adolescents experiencing PTSD symptoms from grief found from this meta-analysis first and foremost documents the urgent need to for more research to understand how to best treat PTSD symptoms among adolescents. In addition, finding non-invasive therapies and adjustment styles for grieving adolescents with PTSD is important.

No significant sex difference was found in the likelihood to display externalized behaviors during grief. It is important to note that externalized expressions of grief included a vast range of behaviors. Behaviors ranged from delinquency and "acting out” to behaviors like self-harm to school truancy and property damage (Shaver, 2013). This finding may be an overall behavioral response of the limbic system overriding the prefrontal cortex in general during adolescence rather than a specific brain region associated with a behavioral response (Blakemore, 2008). Nonetheless, the lack of sex differences in externalized grief is of critical importance for future research. As there are many different kinds of physical behaviors that can be seen with grief, the next steps in understanding externalized grieving patterns is to narrow the externalized behaviors being evaluated. Understanding whether propensities to engage in more nuanced externalized behaviors differ by sex assigned at birth can help practitioners, parents, school counselors and teachers identify when an adolescent is experiencing grief. In addition, as there was no significant difference in externalized behaviors by sex, future research and practice can use this information to acknowledge that all adolescents (not just males) are likely to have externalizing manifestations of their grief. This possibility will allow programs and interventions to channel externalized grief responses into more positive and constructive behaviors. 
In addition to understanding the frequently observed grieving behaviors, intervention and resource strategies have the potential to mitigate harmful grieving behaviors from progressing. On occasion, grief has been seen to manifest into prolonged grief disorder (Melhem et al., 2007) causing substantial separation distress that leaves the individual in a sustained state of shock that has a negative affect on daily life (Prigerson et al., 2009). Complicated grief occurs when a person's grief is so persistent and intense that the individual suffers physical distress, as well as the increased likelihood dying by suicide (Nam, 2016). Addressing sex differences in internalized, externalized, and PTSD behaviors in adolescent grief has the potential to not only assist the adolescent in bridging the gap to achieve a healthy future free of long-term effects of grief, but also stop assist individuals experiencing more intense forms of grief.

This meta-analysis investigated internalizing behaviors, externalizing behaviors, and PTSD symptoms separately in an attempt to exclusively attribute certain grief behaviors with a particular sex. When applying these results to grief support practice, it is important to emphasize that grief is often multifaceted, often with internalizing, externalizing, and PTSD symptoms co-occurring (Javdani et al., 2017). When helping a grieving adolescent, each individual should be assessed independently with the findings of this meta-analysis as a guide.

\section{Limitations}

While this meta-analysis incorporated studies from across the world, studies form Europe and North America were overrepresented. Many cultures and populations were not represented in this study, as grief data was not readily reported in these locations or did not meet the criteria of this meta-analysis. Cultural considerations outside of 
geographical location, such as socioeconomic status, were not well-documented across studies. For this reason, we were not able to examine associations among our outcomes and demographics relating to religion, education, and income, and thus it is a concern that underrepresented populations may not have been adequately represented in this metaanalysis. Thus, the generalizability of our findings is limited to the selected set of studies included in the analysis.

Grief due to the loss of a parent was found to be the most common death among the studies investigating adolescent grief. While information about grief responses to the death of a parent is critically important, results from this meta-analysis may more adequately represent adolescents who are grieving a family member, such as a parent, rather than an individual outside of familial ties such as a teacher or classmate. Further, given the small selection of studies available for inclusion in the study, the analysis was not able to account for the differences by relation of the deceased or cause of death.

\section{Conclusion}

Adolescence is an emotional time of life accompanied by behaviors driven by the limbic system due to an underactive prefrontal cortex (Blackmore, 2008). In addition, internalizing behaviors, externalizing behaviors, and PTSD symptoms are commonly observed among grieving adolescents. Like any life event, grief is complex, but investigating the manifestations of grief during a critical time period in a developing life, interventions can be introduced in order to help the individual adjust for their most optimal life outcomes possible. The results of the study suggest that with the prevalence of adolescent grief and the likely behavioral outcomes associated differs by sex, suggesting that there is much progress to be done to help grieving adolescents. 


\section{References}

Abate, A., Marshall, K., Sharp, C., \& Venta, A. (2017). Trauma and aggression: Investigating the mediating role of mentalizing in female and male inpatient adolescents. Child Psychiatry And Human Development, doi:10.1007/s10578017-0711-6

Angold, A., Costello, E. J., Erkanli, A., \& Worthman, C. M. (1999). Pubertal changes in hormone levels and depression in girls. Psychological Medicine, 29(5), 10431053.

Arain, M., Haque, M., Johal, L., Mathur, P., Nel, W., Rais, A., ... Sharma, S. (2013). Maturation of the adolescent brain. Neuropsychiatric Disease and Treatment, 9, 449-461. http://doi.org/10.2147/NDT.S39776

Archibald, H. C., Bell, D., Miller, C., \& Tuddenham, R. D. (1962). Bereavement in childhood and adult psychiatric disturbance. Psychosomatic Medicine, 24(4), 343351.

Aronfreed, J. (2013). Conduct and conscience: The socialization of internalized control over behavior. New York: Academic Press, Inc.

Blakemore, S. J. (2008). The social brain in adolescence. Nature Reviews Neuroscience, 9(4), 267-277.

Boelen, P. A., \& Spuij, M. (2013). Symptoms of post-traumatic stress disorder in bereaved children and adolescents: Factor structure and correlates. Journal of Abnormal Child Psychology, 41(7), 1097-1108. doi:10.1007/s10802-013-9748-6

Bornstein, M. H., Hahn, C.-S., \& Suwalsky, J. T. D. (2013). Language and Internalizing and Externalizing Behavioral Adjustment: Developmental Pathways from 
Sex Differences in Grief During Adolescence 20

Childhood to Adolescence. Development and Psychopathology, 25(3), 857-878. http://doi.org/10.1017/S0954579413000217

Brent, D. A., Melhem, N. M., Masten, A. S., Porta, G., \& Payne, M. W. (2012).

Longitudinal Effects of Parental Bereavement on Adolescent Developmental Competence. Journal of Clinical Child and Adolescent Psychology : The Official Journal for the Society of Clinical Child and Adolescent Psychology, American Psychological Association, Division 53, 41(6), 778-791.

Bylund Grenklo, T., Kreicbergs, U., Hauksdóttir, A., Valdimarsdóttir, U. A., Nyberg, T., Steineck, G., \& Fürst, C. J. (2013). Self-injury in Teenagers Who Lost a Parent to Cancer: A Nationwide, Population-Based, Long-term Follow-up. JAMA Pediatrics, 167(2), 133-140.

Card, N. A. (2016). Applied meta-analysis for social science research. New York, NY: The Guilford Press

Casey, B.J., Jones, R. M. and Hare, T. A. (2008). The adolescent brain. Annals of the New York Academy of Sciences, 1124, 111-126. doi:10.1196/annals.1440.010

Christakou, A., Halari, R., Smith, A. B., Ifkovits, E., Brammer, M., \& Rubia, K. (2009). Sex-dependent age modulation of frontostriatal and temporo-parietal activation during cognitive control. Neuroimage, 48(1), 223-236. doi:10.1016/j.neuroimage.2009.06.070

Cohen, J. A., \& Mannarino, A. P. (2016). Posttraumatic stress disorder and persistent complex bereavement disorder. In M. K. Dulcan (Ed.), Dulcan's Textbook of Child and Adolescent Psychiatry (pp. 345-364). Arlington, VA, US: American Psychiatric Publishing, Inc. doi:10.1176/appi.books.9781615370306.md16 
Cluver, L., Gardner, F., \& Operario, D. (2007). Psychological distress amongst AIDSorphaned children in urban South Africa. Journal Of Child Psychology And Psychiatry, 48(8), 755-763. doi:10.1111/j.1469-7610.2007.01757.x

Costello, D. J., Pine, D. S., Hammen, C., March, J. S., Plotsky, P. M., Weissman, M. M., \& Leckman, J. F. (2002). Development and natural history of mood disorders. Biological Psychiatry, 52(6), 529-542.

Danielson, C. K., Cohen, J. R., Adams, Z. W., Youngstrom, E. A., Soltis, K., Amstadter, A. B., \& Ruggiero, K. J. (2017). Clinical decision-making following disasters: Efficient identification of PTSD risk in adolescents. Journal of Abnormal Child Psychology, 45(1), 117-129. doi:10.1007/s10802-016-0159-3

Dixon, M. L. (2015). Cognitive control, emotional value, and the lateral prefrontal cortex. Frontiers in psychology, 6.758-759

Draper, A., \& Hancock, M. (2011). Childhood parental bereavement: the risk of vulnerability to delinquency and factors that compromise resilience. Mortality, 16(4), 285-306. doi:10.1080/13576275.2011.613266

Engels, A. S., Heller, W., Spielberg, J. M., Warren, S. L., Sutton, B. P., Banich, M. T., \& Miller, G. A. (2010). Co-occurring anxiety influences patterns of brain activity in depression. Cognitive, Affective \& Behavioral Neuroscience, 10(1), 141-156. http://doi.org/10.3758/CABN.10.1.141

Ens, C., \& Bond, J. J. (2005). Death anxiety and personal growth in adolescents experiencing the death of a grandparent. Death Studies, 29(2), 171-178. doi:10.1080/07481180590906192 
Frodl, T., Schaub, A., Banac, S., Charypar, M., Jäger, M., Kümmler, P., ...Meisenzahl, E. M. (2006). Reduced hippocampal volume correlates with executive dysfunctioning in major depression. Journal of Psychiatry and Neuroscience, 31(5), 316-325.

Garmezy, N. and Masten, A. (1994) Chronic adversities. In M. Rutter, E. Taylor, \& L. Hersov (Eds.), Child and Adolescent Psychiatry: Modern Approaches (3rd Ed.) (pp. 191-208). London: Blackwell.

Gearing, R. E., MacKenzie, M. J., Ibrahim, R. W., Brewer, K. B., Batayneh, J. S., \& Schwalbe, C. J. (2015). Stigma and mental health treatment of adolescents with depression in Jordan. Community Mental Health Journal, 51(1), 111-117. doi:10.1007/s10597-014-9756-1

Gerhardt, C. A., Fairclough, D. L., Grossenbacher, J. C., Barrera, M., Gilmer, M. J., Foster, T. L., \& Vannatta, K. (2012). Peer relationships of bereaved siblings and comparison classmates after a child's death from cancer. Journal Of Pediatric Psychology, 37(2), 209-219. doi:10.1093/jpepsy/jsr082

Giedd, J. N., Castellanos, F. X., Rajapakse, J. C., Vaituzis, A. C., \& Rapoport, J. L. (1997). Sexual dimorphism of the developing human brain. Progress in NeuroPsychopharmacol and Biological Psychiatry, 21, 1185-1200.

Giedd, J. N. (2004). Structural magnetic resonance imaging of the adolescent brain. Annals of the New York Academy of Sciences, 1021, 77-85. doi:10.1196/annals.1308.009

Giedd, J.N., Rapoport, J.L. (2010). Structural MRI of pediatric brain development: What have we learned and where are we going? Neuron, 67, 728-734. 
Green, M., Osterweis, M., Solomon, F. (1984). Bereavement: Reactions, consequences, and care. Washington, DC: National Academies Press

Gur, R. C., Gunning-Dixon, F., Bilker, W. B., Gur, R. E. (2002). Sex differences in temporo-limbic and frontal brain volumes of healthy adults. Cerebral Cortex, 12, 998-1003. 10.1093/cercor/12.9.998

Haine, R. A., Wolchik, S. A., \& Sandler, I. N. (2006). Positive Parenting as a Protective Resource for Parentally Bereaved Children. Death Studies, 30(1), 1-28.

Hamilton, J. P., Siemer, M., \& Gotlib, I. H. (2008). Amygdala volume in major depressive disorder: A meta-analysis of magnetic resonance imaging studies. Molecular Psychiatry, 13(11), 993-1000. doi:10.1038/mp.2008.57

Herres, J., Williamson, A. A., Kobak, R., Layne, C. M., Kaplow, J. B., Saltzman, W. R., \& Pynoos, R. S. (2016). Internalizing and externalizing symptoms moderate treatment response to school-based trauma and grief component therapy for adolescents. School Mental Health, 1-10 doi:10.1007/s12310-016-9204-1

Hobfoll, S. E. (1989). Conservation of resources. A new attempt at conceptualizing stress. The American Psychologist, 44(3), 513-524.

Imel, Z. E., Laska, K., Jakupcak, M., Simpson, T. L. (2013). Meta-analysis of dropout in treatments for posttraumatic stress disorder. Journal of Consulting and Clinical Psychology, 81, 394-404. doi:10.1037/a0031474

Javdani, S., Sadeh, N., Donenberg, G. R., Emerson, E. M., Houck, C., \& Brown, L. K. (2017). Affect recognition among adolescents in therapeutic schools: Relationships with posttraumatic stress disorder and conduct disorder symptoms. Child and Adolescent Mental Health, 22(1), 42-48. doi:10.1111/camh.12198 
Jensen, T. K., Fjermestad, K. W., Granly, L., \& Wilhelmsen, N. H. (2015). Stressful life experiences and mental health problems among unaccompanied asylum-seeking children. Clinical Child Psychology And Psychiatry, 20(1), 106-116. doi:10.1177/1359104513499356

Kalter, N., Lohnes, K. L., Chasin, J. (2002). The adjustment of parentally bereaved childen: I. Factors assocated with short-term adjustment. Omega: The Journal of Death and Dying, 46(1), 15-34

Koenigs, M., \& Grafman, J. (2009). The functional neuroanatomy of depression: Distinct roles for ventromedial and dorsolateral prefrontal cortex. Behavioural Brain Research, 201(2), 239-243. http://doi.org/10.1016/j.bbr.2009.03.004

Leonard, C.M., Towler, S., Welcome, S., Halderman, L.K., Otto, R., Eckert, M.A., \& Chiarello, C. (2008). Size matters: Cerebral volume influences sex differences in neuroanatomy. Cerebral Cortex, 18, 2920-2931. doi:10.1093/cercor/bhn052

Little, M., Sandler, I. N., Wolchik, S. A., Tein, J., \& Ayers, T. S. (2009). Comparing cognitive, relational and stress mechanisms underlying gender differences in recovery from bereavement-related internalizing problems. Journal Of Clinical Child And Adolescent Psychology: The Official Journal For The Society Of Clinical Child And Adolescent Psychology, American Psychological Association, Division 53, 38(4), 486-500. doi:10.1080/15374410902976353

Markusen, E., \& Fulton, R. (1971). Childhood bereavement and behavior disorders: A critical review. Omega: The Journal of Death and Dying, 2, 107-117. 
McGuire J. T., \& Botvinick M. M. (2010). Prefrontal cortex, cognitive control, and the registration of decision costs. Procedings of the National Academy of Sciences of the United States of America, 107, 7922-7926. doi:10.1073/pnas.0910662107

Melhem, N. M., Moritz, M. P. H., Walker, M. S. W., Shear, M. K., \& Brent, D. (2007). Phenomenology and correlates of complicated grief in children and adolescents. Journal of the American Academy of Child and Adolescent Psychiatry, 46, 493499.

Melhem, N.M., Porta, G., Shamseddeen, W., Walker Payne M., Brent D.A. (2011). Grief in children and adolescents bereaved by sudden parental death. Archives of General Psychiatry, 68(9), 911-919. doi:10.1001/archgenpsychiatry.2011.101

Mitchell, A. M., \& Terhorst, L. (2017). PTSD symptoms in survivors bereaved by the suicide of a significant other. Journal of The American Psychiatric Nurses Association, 23(1), 61-65. doi:10.1177/1078390316673716

Nam, I. (2016). Suicide bereavement and complicated grief: Experiential avoidance as a mediating mechanism. Journal of Loss And Trauma, 21(4), 325-334. doi:10.1080/15325024.2015.1067099

Neufang, S., Specht, K., Hausmann, M., Güntürkün. O., Herpertz-Dahlmann, B., Fink G.R., \& Konrad, K. (2009). Sex differences and the impact of steroid hormones on the developing human brain. Cerebral Cortex, 19, 464-473.

Nieuwenhuys, R. (1996). The greater limbic system, the emotional motor system and the brain. Progress in Brain Research, 107, 551-580. 
Nuñez, J. L., Lauschke, D. M., \& Juraska, J. M. (2001). Cell death in the development of the posterior cortex in male and female rats. The Journal of Comparative Neurology, 436(1), 32-41.

Paus, T. (2010). Sex differences in the human brain: A developmental perspective. Progress in Brain Research, 186: 13-28.

Paus, T., Wong, A. P., Syme, C., \& Pausova, Z. (2017). Sex differences in the adolescent brain and body: Findings from the Saguenay youth study. Journal of Neuroscience Research, 95(1-2), 362-370.

Perrin, J. S., Hervé, P., Leonard, G., Perron, M., Pike, G. B., Pitiot, A., \& ... Paus, T. (2008). Growth of white matter in the adolescent brain: Role of testosterone and androgen receptor. The Journal of Neuroscience, 28(38), 9519-9524. doi:10.1523/JNEUROSCI.1212-08.2008

Perry, D. G., \&Pauletti, R. E. (2011). Gender and adolescent development. Journal of Research on Adolescence, 21, 61-74. doi:10.1111/j.1532-7795.2010.00715.x

Pinos, H., Collado, P., Rodríguez-Zafra, M., Rodríguez, C., Segovia, S., \& Guillamón, A. (2001). The development of sex differences in the locus coeruleus of the rat. Brain Research Bulletin, 56(1), 73-78.

Prigerson, H. G., Horowitz, M. J., Jacobs, S. C., Parkes, C. M., Aslan, M., Goodkin, K., \& Maciejewski, P. K. (2009). Prolonged grief disorder: psychometric validation of criteria proposed for DSM-V and ICD-11. PLoS Medicine 6(8) 1549-1676: e1000121. 
Rankin, S. L., Partlow, G. D., McCurdy, R. D., Giles, E. D., \& Fisher, K. S. (2003). Postnatal neurogenesis in the vasopressin and oxytocin-containing nucleus of the pig hypothalamus. Brain Research, 971(2), 189-196.

Reijneveld, S. A., Wiegersma, P. A., Ormel, J., Verhulst, F. C., Vollebergh, W. M., \& Jansen, D. C. (2014). Adolescents’ use of care for behavioral and emotional problems: Types, trends, and determinants. Plos ONE, 9(4), 1-11. doi:10.1371/journal.pone.0093526

Riva, D., Giorgi, C. (2000). The cerebellum contributes to higher functions during development: Evidence from a series of children surgically treated for posterior fossa tumours. Brain,123(Pt 5),1051-1061.

Romeo, R. D. (2013). The teenage brain: The stress response and the adolescent brain. Current Directions in Psychological Science, 22(2), 140-145. http://doi.org/10.1177/0963721413475445

Ruigrok, A. V., Salimi-Khorshidi, G., Lai, M., Baron-Cohen, S., Lombardo, M. V., Tait, R. J., \& Suckling, J. (2014). A meta-analysis of sex differences in human brain structure. Neuroscience and Biobehavioral Reviews, 39, 34-50. doi:10.1016/j.neubiorev.2013.12.004

Schneiderman, N., Ironson, G., \& Siegel, S. D. (2005). STRESS AND HEALTH: Psychological, Behavioral, and Biological Determinants. Annual Review of Clinical Psychology, 1, 607-628.

Seligman, R., Gleser, G., \& Rauh, J. (1974) The effect of earlier parental loss in adolescence. Archives of General Psychiatry, 31, 475-479.

Shaver, A. E. (2004). Patterns of rule-violating behavior in children and adolescents. 
Dissertation Abstracts International, 65, 452.

Shifflet-Chila, E. D., Harold, R. D., Fitton, V. A., \& Ahmedani, B. K. (2016). Adolescent and family development: Autonomy and identity in the digital age. Children and Youth Services Review, 70, 364-368.

Siddaway, A. P., Wood, A. M., Schulz, J., \& Trickey, D. (2015). Evaluation of the CHUMS Child Bereavement Group: A Pilot Study Examining Statistical and Clinical Change. Death Studies, 39(1-5), 99-110. doi:10.1080/07481187.2014.913085

Steenkamp, M. M., Litz, B. T., Hoge, C. W., \& Marmar, C. R. (2015). Psychotherapy for military-related PTSD: A review of randomized controlled trials. Journal of the American Medical Association, 315, 489-500. doi:10.1001/jama.2015.8370

Stikkelbroek, Y., Bodden, D. M., Reitz, E., Vollebergh, W. M., \& van Baar, A. L. (2016). Mental health of adolescents before and after the death of a parent or sibling. European Child \& Adolescent Psychiatry, 25(1), 49-59. doi:10.1007/s00787-0150695-3

Tau, G. Z., \& Peterson, B. S. (2010). Normal development of brain circuits. Neuropsychopharmacology, 35(1), 147-168. doi:10.1038/ npp.2009.115.

Thapar, A., Collishaw, S., Pine, D. S., \& Thapar, A. K. (2012). Depression in adolescence. Lancet, 379, 1056-1067. doi:10.1016/S0140-6736(11)60871-4

Usami, M., Iwadare, Y., Kodaira, M., Watanabe, K., Aoki, M., Katsumi, C., \& ... Saito, K. (2012). Relationships between Traumatic Symptoms and Environmental Damage Conditions among Children 8 Months after the 2011 Japan Earthquake and Tsunami. Plos ONE, 7(11), 1-7. doi:10.1371/journal.pone.0050721 
Worden, W. (2003). Grief counseling and grief therapy: A handbook for the mental health practitioner (3rd ed). Boston, MA: Psychology Press. 


\section{Figure 1. Stem-and-Leaf Plots}

\begin{tabular}{|l|c|l|}
\hline \multicolumn{3}{|c|}{ Internalizing Behaviors } \\
\hline Adolescent males & & Adolescent females \\
\hline & 0.0 & \\
\hline 1 & 0.1 & \\
\hline & 0.2 & 3 \\
& 0.3 & 4 \\
\hline & 0.4 & 1 \\
\hline 7 & 0.6 & 5 \\
\hline & 0.7 & \\
\hline & & \\
\hline & & \\
\hline
\end{tabular}

\begin{tabular}{|r|c|l|}
\hline \multicolumn{3}{|c|}{ Externalizing Behaviors } \\
\hline Adolescent males & & Adolescent females \\
\hline 9 & 0.0 & 0 \\
\hline 6 & 0.1 & \\
\hline 0 & 0.2 & \\
\hline 1 & 0.3 & 8 \\
\hline & 0.4 & \\
\hline 4 & 0.5 & 2 \\
\hline & 0.6 & \\
\hline & 0.7 & 0 \\
\hline & & \\
\hline
\end{tabular}


Table 1.

\begin{tabular}{|c|c|c|c|c|c|c|c|c|}
\hline & & & & & & \multicolumn{3}{|c|}{ Cohen's $d$} \\
\hline Study \# & Citation & Total $n$ & $\begin{array}{c}\text { Age } \\
\text { Range }\end{array}$ & $\begin{array}{c}\% \\
\text { Male }\end{array}$ & Who Died & Internalizing & Externalizing & PTSD \\
\hline 1 & $\begin{array}{l}\text { Culver et al., } \\
2007\end{array}$ & 747 & $10-19$ & 57.0 & parent & 0.34 & -0.9 & 0.16 \\
\hline 2 & $\begin{array}{l}\text { Stikkelbroek et } \\
\text { al., } 2016\end{array}$ & 70 & $10-19$ & 48.3 & parent/sibling & 0.65 & -0.2 & - \\
\hline 3 & $\begin{array}{l}\text { Siddaway et al., } \\
2015\end{array}$ & 168 & $9-15$ & 44.0 & parent/sibling/grandparent & - & 0.52 & - \\
\hline 5 & $\begin{array}{l}\text { Boelen \& Spuij, } \\
2013\end{array}$ & 332 & 8-18 & 43.1 & parent, sibling, relative & - & - & 0.35 \\
\hline 6 & $\begin{array}{l}\text { Bylund et al., } \\
2013\end{array}$ & 622 & $13-16$ & 49.0 & parent & - & 0.7 & - \\
\hline 9 & Little et al, 2009 & 109 & $8-16$ & 52.0 & parent & 0.23 & - & - \\
\hline 10 & Haine et al., 2006 & 313 & 8-16 & 54.0 & parent, sibling, grandparent & -0.11 & 0.0 & - \\
\hline 11 & $\begin{array}{l}\text { Ens \& Bond, } \\
2005\end{array}$ & 124 & $11-18$ & 46.0 & grandparent & 0.407 & - & - \\
\hline 12 & Shaver, 2004 & 368 & $5-17$ & 52.0 & parent & - & -0.54 & - \\
\hline 13 & $\begin{array}{l}\text { Kalter et al., } \\
2002\end{array}$ & 19 & $12-16$ & 42.0 & parent & -0.67 & 0.38 & - \\
\hline 14 & $\begin{array}{l}\text { Gerhardt et al., } \\
2012\end{array}$ & 105 & 8-17 & 46.0 & sibling & - & -0.31 & - \\
\hline
\end{tabular}


Sex Differences in Grief During Adolescence 32 